\title{
EFEITO DO RALEIO MANUAL EM FRUTOS DE AMEIXEIRA JAPONESA (PRUNUS SALICINA LIND) SOBRE ALGUMAS QUALIDADES
}

Iohann Metzger Bauchrowitz ${ }^{1}$, Luciane Curtes Porfírio da Silva ${ }^{1}$, Clandio Medeiros da Silva ${ }^{2}$, André Luiz Oliveira de Francisco ${ }^{2}$, Tracy Paola Maçaneiro ${ }^{1}$

Centro de Ensino Superior dos Campos Gerais - CESCAGE, Curso de Agronomia, Ponta Grossa, PR. Instituto Agronômico do Paraná-IAPAR, PR.E-mail: iohannbauchrowitz@gmail.com

\section{RESUMO}

A fruticultura de clima temperado possui grande potencial para desenvolvimento no Brasil, o uso de produtos químicos cada vez mais aumenta nos dias atuais podendo se tonar um problema se utilizados de forma errada, por isto a utilização de outras formas de realização de tratos culturais como é o caso do raleio manual em frutos apresenta-se como uma alternativa para pequenas áreas produtoras. Este trabalho teve como objetivo analisar as datas de início e final dos ciclos de florescimento e frutificação e algumas e qualidades físicas e químicas em frutos de ameixeira japonesa (Prunus salicina Lind) assim como a influência do raleio manual nestas qualidades nos frutos obtidos de diferentes acessos de ameixa produzidos pelo IAPAR. O experimento foi realizado na cidade de Ponta Grossa-PR no Polo Regional de Pesquisas do IAPAR. 0 experimento foi realizado em esquema fatorial $7 \times 2$, composto de sete acessos de ameixeira japonesa (Prunus salicina Lind) e dois tratamentos com realização do raleio manual nos frutos e sem realização do raleio manual e seis repetições. As análises realizadas foram data de início e final do florescimento e início e final frutificação, após a maturação os frutos foram colhidos e analisados as características de diâmetro dos frutos, massa dos frutos, massa do caroço massa da polpa dos frutos, sólidos solúveis totais, acidez total titúlavel e ratio. O raleio manual realizados nos frutos de ameixeira apresentou um acréscimo significativo nos valores do diâmetro dos frutos e na massa do frutos, massa do caroço e massa da polpa, este aumento ocorreu devido principalmente a retirada de frutos diminuindo a competição por seiva e fotoassimilados entre os frutos, entretanto os frutos não apresentaram variações nos resultados nas análises de sólidos solúveis totais, acidez total titúlavel e ratio mostrando que mesmo com a realização deste trato cultura não afetou estas características, com isso é possível concluir que os acessos estudados apresentam capacidade de lançamento como novas cultivares adaptadas ao clima do município de Ponta Grossa-PR, e que o raleio manual nos frutos é uma alternativa para a realização pequenas áreas trazendo resultados positivos nas qualidades físicas dos frutos.

Palavras-chaves: fenologia; tratos culturais; maturação dos frutos.

\section{EFFECT OF MANUAL THINNING ON JAPANESE PLUM FRUITS (PRUNUS SALICINA LIND) ON SOME QUALITIES}

\begin{abstract}
Temperate fruit growing has great potential for development in Brazil, the use of chemical products is increasing more and more in the present day, being a problem if used in a wrong way, therefore the use of other forms of cultural the case of manual thinning in fruits presents itself as an alternative to small producing areas. The objective of this work was to analyze the start and end dates of flowering and fruiting cycles and some physical and chemical qualities of Japanese plum fruits (Prunus salicina Lind) as well as the influence of manual thinning on these qualities in fruits obtained from different accessions of plum produced by IAPAR. The experiment was carried out in the city of Ponta Grossa-PR at the Regional Research Center of IAPAR. The experiment was carried out in a 7x2 factorial scheme, composed of seven Japanese plum accesses (Prunus salicina Lind) and two treatments with manual thinning in the fruits and without manual thinning and six replications. The fruits were harvested and the characteristics of fruit diameter, fruit mass, seed mass, fruit pulp mass, total soluble solids, titrizable total acidity and ratio. The manual thinning performed on the plum fruits showed a significant increase in fruit diameter and fruit mass, stone mass and pulp mass. This increase was mainly due to the removal of fruits, reducing the competition for
\end{abstract}


sap and photoassimilates between the fruits. However, the fruits did not show any variation in the results in the analyzes of total soluble solids, total acidity and titrable ratio, showing that even with the accomplishment of this tract culture did not affect these characteristics, with this it is possible to conclude that the accesses studied present a capacity of launching as new cultivars adapted to the climate of the city of Ponta Grossa-PR, and that the manual thinning in the fruits is an alternative to the realization of small areas bringing positive results in the physical qualities of the fruits.

Keywords: phenology; cultural treatments; fruit ripening.

\section{INTRODUÇÃO}

A fruticultura de clima temperado é uma alternativa para a diversificação da produção nas propriedades principalmente das Regiões Sul e Sudeste do Brasil, principalmente pelo fator clima que se apresenta como sendo um fator limitante para a produção destas frutíferas (FACHINELLO et al., 2011).

$\mathrm{Na}$ fruticultura de clima temperado, as frutíferas de caroço a ameixa apresentam-se como uma alternativa de grande aceitação para os produtores de frutas, sendo que entre as frutíferas de caroço mais cultivadas nos estados do Sul e Sudestes destacam-se o pêssego como sendo a frutífera de maior importância seguida pela ameixa e nectarina (EPAGRI, 2010).

Entre os estados produtores de frutas de caroço, os maiores produtores são os estados do Rio Grande do Sul, seguido de Santa Catarina e Paraná (SEAB, 2012). No estado do Paraná, a ameixeira é cultivada em uma área de 759 ha com uma produção em toneladas de 12.341 representando aproximadamente $0.7 \%$ do total de frutos produzidos no estado (SEAB, 2013).

As principais cultivares utilizadas comercialmente no estado do Paraná, são as cultivares Irati (PAVANELLO; AYUB, 2012) e Reubennel (PAVANELLO; AYUB, 2014; OLIVEIRA et al., 2014), não sendo resistentes a doenças principalmente a escaldadura das folhas (Xylella fastidiolsa) sendo as que apresentam capacidade de produção em regiões com climas mais quentes, estas variedades apresentam grande potencial produtivo, intentando necessitando de tratos culturais como o raleio para a produção de frutos com qualidade (ARHENS et al., 2014).
Existem atualmente várias formas de realização do raleio em ameixeiras, entretendo a principal forma de realização e através do raleio químico (PAVANELLO; AYUB, 2012), podendo ser problema ambiental quando mal realizado. Devido a este fato o raleio manual é uma alternativa utilizadas para produtores que apresentam menores áreas cultivadas, e que possuem uma quantidade de mão de obra.

Empresas de pesquisa, principalmente governamentais vem desenvolvimento a anos programas de melhoramento genético, visando a obtenção de novas cultivares de ameixa adaptadas as diferentes condições climáticas do Brasil ou a resistência a doenças e melhora na qualidade dos frutos (CASTRO, 2003).

O trabalho teve como objetivo analisar as datas de início e final dos ciclos de florescimento e frutificação assim como algumas características físicas e químicas dos frutos de ameixeira japonesa (Prunus salicina Lind) como a influência do raleio manual na qualidade dos frutos obtidos de diferentes acessos produzidos pelo Instituto Agronômico do Paraná-IAPAR durante seu programa de melhoramento genético.

\section{MATERIAIS E MÉTODOS}

A atividade foi realizada, no IAPARInstituto Agronômico do Paraná, Pólo Regional de Pesquisa de Ponta Grossa situada às margens da BR 376, na cidade de Ponta Grossa, Paraná, com altitude aproximada de $838 \mathrm{~m}$, o clima da região de acordo com a classificação de Koppen é do tipo $\mathrm{Cfb}$, subtropical úmido, com temperatura média anual de $18^{\circ} \mathrm{C}$ e precipitação média anual de aproximadamente $1.550 \mathrm{~mm}$ (IAPAR, 2000) (Gráfico 1). 
Gráfico 1. Dados de temperatura no local do experimento durante a safra de 2014/2015.

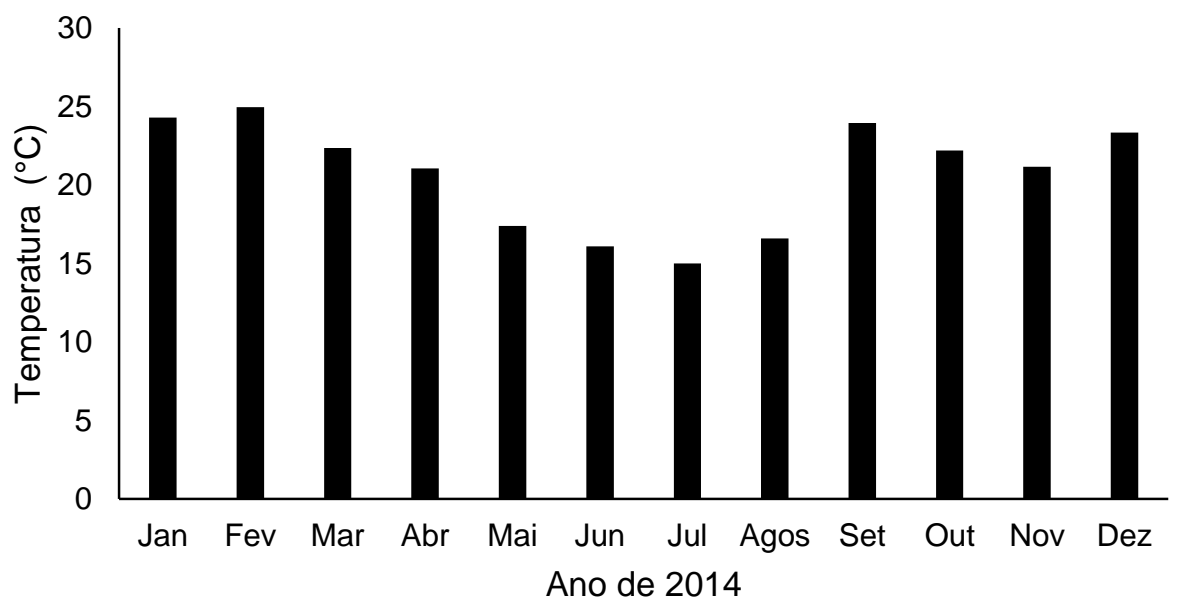

O experimento foi realizado na safra de 2014/2015 em esquema fatorial $7 \times 2$, composto por sete acessos de ameixa japonesa sendo eles G31, G9, G22, G3, G7, G21 e G8 (Prunus salicina Lind) plantados em espaçamento de 5,00 metros entre linhas e 1,50 metros entre plantas, submetidos a dois tratos culturais sendo: $\mathrm{T} 1=\mathrm{A}$ utilização do raleio manual em frutos quando estes se encontravam com diâmetro de $1 \mathrm{~cm}$ em cada um dos acessos e T2 = A testemunha, na qual não foi realizado nenhum trato cultural relacionado com o raleio nos frutos, com 6 repetições cada tratamento totalizando 84 unidade ou parcelas.

Os frutos foram colhidos quando apresentaram coloração de epiderme entorno de $30 \%$ de sua coloração final. Foram coletadas e analisadas as características de diâmetro dos frutos (DF), massa dos frutos (MF), massa dos caroços (MC), e massa da polpa (MP), e com os dados do diâmetro dos frutos foi determinado o calibre dos frutos, utilizando os padrões recomendados pela (EMATE, 2001).

E qualidades químicas dos frutos as análises realizadas nos frutos, foram de sólidos solúveis totais (sst), acidez total titulável (att) e ratio, obtido pela relação sst/att. Os valores de sólidos solúveis totais foram obtidos através de amostra do suco processado dos frutos a analisados em refratrometro digital (RT-90ATC), com valores corrigidos para $20^{\circ} \mathrm{C}$.

Acidez total titulavel será terminado por titulação de $10 \mathrm{ml}$ do processo e $90 \mathrm{ml}$ de água com hidróxido de Sódio $(\mathrm{NaOH}) \quad 0,1 \mathrm{~N}$ padronizado, até $\mathrm{o}$ pH 8,1 e expressa em porcentagem de ácido málico.

\% de ác. Málico $=\mathrm{Vb}(\mathrm{ml}) \cdot \mathrm{Nb} \cdot 0,067 \cdot 100$ 10
Onde:

$\mathrm{Vb}=$ Volume da base $(\mathrm{NaOH})$ em $\mathrm{ml}$

$\mathrm{Nb}=$ Normalidade de $\mathrm{NaOH}$ em $\mathrm{N}$

0,067=miliequivalente para ácido málico

Os dados obtidos durante as análises foram submetidos a análise estatística pelo programa SISVAR 5.6 a teste de Tukey a $5 \%$ de probabilidade (FERREIRA, 2014).

\section{RESULTADOS E DISCUSSÕES}

$\mathrm{Na}$ tabela 1 são apresentadas as informações sobre os ciclos dos acessos, tanto com o início do florescimento dos diferentes acessos de ameixa, como o final dos mesmos, sendo também é observado as datas de início e final dos ciclos de frutificação dos acessos.

É possível observar que os ciclos de florescimento de todos os acessos ocorrem em um período curto de tempo, ambos com variação menor do que 30 dias, ocorrendo principalmente no mês de julho e primeira semana do mês de agosto de 2014, este fato ocorre porque todos os acessos apresentados na Tabela 1 apresentaram como principal objetivo durante a realização de seus cruzamentos a obtenção de acessos de ameixa com baixa exigência em frio, ou que apresentem seus início do desenvolvimento nos momentos finais do inverno quando o risco de geadas diminui consideravelmente.

Os ciclos de florescimento em todos os acessos são considerados ciclos rápidos, devido ao seu curto espaço de tempo necessário para que as gemas apresentem seu desenvolvimento, o estágio de inchamento de gemas até a queda das pétalas. Estes ciclos em todos os acessos não apresenta um período maior do que 30 dias, podendo ocorrem variação em períodos menores devido a diferença existente entre as 
características dos acessos. Os ciclos de frutificação apresentam grande variação na quantidade de dias necessários para que ocorra o completo desenvolvimento do fruto após o final da florada até o início da colheita dos frutos.

Esta variação nas datas de final de frutificação pode ser observada durante o trabalho realizado por Oliveira et al. (2012), quando este analisou o ciclo de frutificação da ameixa da cultivar Irati e Reubennel, sendo a primeira com produção ou início da colheita próximo ao dia 10 de novembro e a segunda cultivar com início de colheita próximo do dia 1 de dezembro.

Os resultados de início do florescimento até a final da frutificação dos acessos estudados apresentam á datas obtidas em diferentes cultivares de ameixa produzidas no estado de São Paulo, variedades estas que entre as estudadas por Chagas (2008) podemos mencionar a Kelsey Paulista com início de colheita em 7 de janeiro quando aplicado indutor de brotação, e a cultivar Januária com início também no mesmo dia da Kelsey Paulista em 1 de janeiro. Em diferentes genótipos de ameixeira é possível observar que as datas de inicio e final dos ciclos de florescimento e frutificação apresentam variações causado principalmente pela diferença no cruzamento que originou os genótipos (BAUCHROWITZ et al., 2017).

Tabela 1. Dados sobre inícios e finais dos ciclos de florescimento e frutificação dos diferentes acessos

\begin{tabular}{c|c|c|c|c}
\hline Acesso & Início Florescimento & Final Florescimento & Início Frutificação & Final Frutificação \\
\hline G31 & $21 / 07 / 2014$ & $26 / 08 / 2014$ & $27 / 08 / 2014$ & $05 / 12 / 2014$ \\
G9 & $09 / 07 / 2014$ & $13 / 08 / 2014$ & $14 / 08 / 2014$ & $25 / 11 / 2014$ \\
G22 & $01 / 08 / 2014$ & $02 / 09 / 2014$ & $02 / 09 / 2014$ & $16 / 12 / 2014$ \\
G3 & $14 / 07 / 2014$ & $14 / 08 / 2014$ & $15 / 08 / 2014$ & $20 / 11 / 2014$ \\
G7 & $21 / 07 / 2014$ & $25 / 08 / 2014$ & $26 / 08 / 2014$ & $29 / 11 / 2014$ \\
G21 & $03 / 08 / 2014$ & $31 / 08 / 2014$ & $01 / 09 / 2014$ & $22 / 11 / 2014$ \\
G8 & $06 / 07 / 2014$ & $31 / 07 / 2014$ & $01 / 08 / 2014$ & $29 / 10 / 2014$ \\
\hline
\end{tabular}

Com exceção a característica do MC, a qual apresenta um aumento que não é desejado pelos consumidores pelo fato de o caroço não ser uma parte utilizada no consumo dos frutos de ameixa, os resultados da realização do raleio manual nos frutos de ameixa dos acessos trabalhos apresentou-se como sendo uma alternativa para um acréscimo na qualidade dos frutos, visto que este aumento em algumas das características será de grande importância no momento da classificação dos frutos para o comercio, classificação esta que será apresentada posteriormente na tabela 2 .

Quando observamos a característica do MF podemos notar que apenas a testemunhas de dois dos acessos estudados quando a influência do raleio manual apresentam seus valores iguais ou menores do que $40 \mathrm{~g}$ por frutos, exceções são os acessos G22 e G3. Os resultados obtidos tanto para os frutos nos quais o raleio foi realizado assim com sua testemunha apresentam um valores de massa nos frutos superiores aos obtidos na cultivar Irati quando esta foi submetida ao raleio químico a qual apresentou como seu valor de maior peso 40g (PAVANELO;
AYUB, 2012), aumento este pode estar relacionado com fatores genéticos dos genótipos que apresentaram cruzamento diferentes, ou pelo fato que o raleio manual retirou uma quantidade de frutos superior ao químico, em frutosda cultivar Reubennel apresentam variação nos valores de 20 a $70 \mathrm{~g}$ no MF quando realizado o raleio químico (PAVANELLO; AYUB, 2014).

Quando observamos os valores obtidos para a característica MF apresentado na gráfico 2 os melhores resultados obtidos nos acessos apresentam valores superiores aos valores da Reubennel, sendo que o G9 apresenta valores de MF médio nos frutos de 93,48 g.

A característica de MC é a única entre as características físicas dos frutos de ameixa dos diferentes acessos, que apresenta um aumento em grande parte dos valores, entretanto este aumento não como uma qualidade ideal para os frutos, devido principalmente ao fato que o caroço dos frutos de ameixa sejam elas destinadas para a indústria ou para o consumo "in-natura" em sua grande maioria são descartados. 
E possível observar na tabela 02 que a variação no Massa dos caroços dos frutos de ameixa dos diferentes acessos apresenta valores entre $1,16 \mathrm{~g}$, sendo o menor no genótipo G22 quando não submetido ao raleio manual, e de 3,27 g no genótipo G31 quando este é submetido ao trato cultural do raleio.

A característica relacionada ao caroço dos frutos é mais utilizada na produção de pêssegos do que em ameixa devido que na cultura do pêssego o caroço apresenta um papel de grande importância, principalmente no momento de classificação dos frutos através da polpa aderente ou não aderente (COSTA, 2011).

A alteração nos valores de $\mathrm{MC}$ dos frutos de ameixa, ocorre principalmente pela diminuição da competição dos frutos por espaço e fotoassimilados, e pelo maior desenvolvimento dos frutos (FACHINELLO et al., 2008).

A literatura apresenta poucas informações sobre a influência do Massa dos caroços dos frutos de ameixa, relatos produzidos por Fonseca et al. (1994) mencionam que os caroços devem apresentar um valor menor do que $10 \%$ do peso do fruto total, esta quantidade de Massa dos caroços e influenciada principalmente pela quantidade de ramos e de frutos produzidos na planta (PAIVA et al., 1994). Enquanto nos acessos utilizados neste experimento o maior PC foi de $5,44 \%$ o massa do fruto, em frutos do um acesso de ameixeira Byron é possível observar o aumento da massa dos frutos dependendo do momento de realização do raleio manual (BAUCHROWITZ et al., 2017).

Neste trabalho de estudo utilizando diferentes acessos submetidos ou não ao trato cultural do raleio, os quais os valores são apresentados na tabela 02 , podemos notar que estes valores são superiores aos obtidos por Chagas (2008), aonde os valores do Massa dos caroços nas cultivares do estado de São Paulo foram de 0,96 g na cultivar Jánuario.

A característica de Massa da polpa (MP) de ameixa dos diferentes acessos apresenta uma variação entre os valores de $37,97 \mathrm{~g}$ quando os frutos não são submetidos ao trato cultural como ocorre no genótipo G21 até valores de $92,00 \mathrm{~g}$ de massa nos frutos, no genótipo G9. Os valores de, MP são os valores obtidos na polpa do fruto, estes valores apresentam como expressão a quantidade de polpa a qual cada um dos frutos, possui após a retirada do seu caroço.

Em pesquisas realizadas nas cultivares de ameixa Reubennel e Harry Pickstone quando cultivadas na região de Santa Catarina, os valores de, MP destes frutos foram de $62,8 \mathrm{~g}$ e $72,5 \mathrm{~g}$, respectivamente para estas cultivares (DUCROQUET, 1994). Sendo maiores que várias, MP obtidas com o tratamento de raleio manual.na cultivar Gulfblaze (FLA 87-7) quando produzidos em condições ideais de desenvolvimento, condições estas com todos os tratos culturais realizados, principalmente o trato cultura do raleio, a quantidade de massa nos frutos desta cultivar é de $80 \mathrm{~g}$ (BARBOSA et al., 2001).

Segundo Chagas (2008), quando analisou algumas cultivares adaptadas a região de São Paulo os melhores resultados para a característica de massa as cultivares Januário e Gulfblaze e Carmesim apresentam valores de $61,98 \mathrm{~g}, 56,86$ g e $55,17 \mathrm{~g}$ respectivamente.

Já as cultivares que apresentou os menores resultados de massa dos frutos de ameixa nas diferentes cultivares estudadas por Chagas (2008), foi de 31,60 g valor este obtido na cultivar Kelsey Paulista. Os valores obtidos no trabalho utilizados os diferentes acessos submetidos ao trato cultural do raleio manual ou não são todos superiores aos comparados a cultivar Kelsey Paulista (CHAGAS, 2008). 
Gráfico 2. Dados de massa dos caroços (A), Massa dos frutos (B), Massa da polpa (C) e Diametro dos frutos (D), obtidos em diferentes acessos de ameixeira japonesa tratados ou não com o raleio manual em frutos.
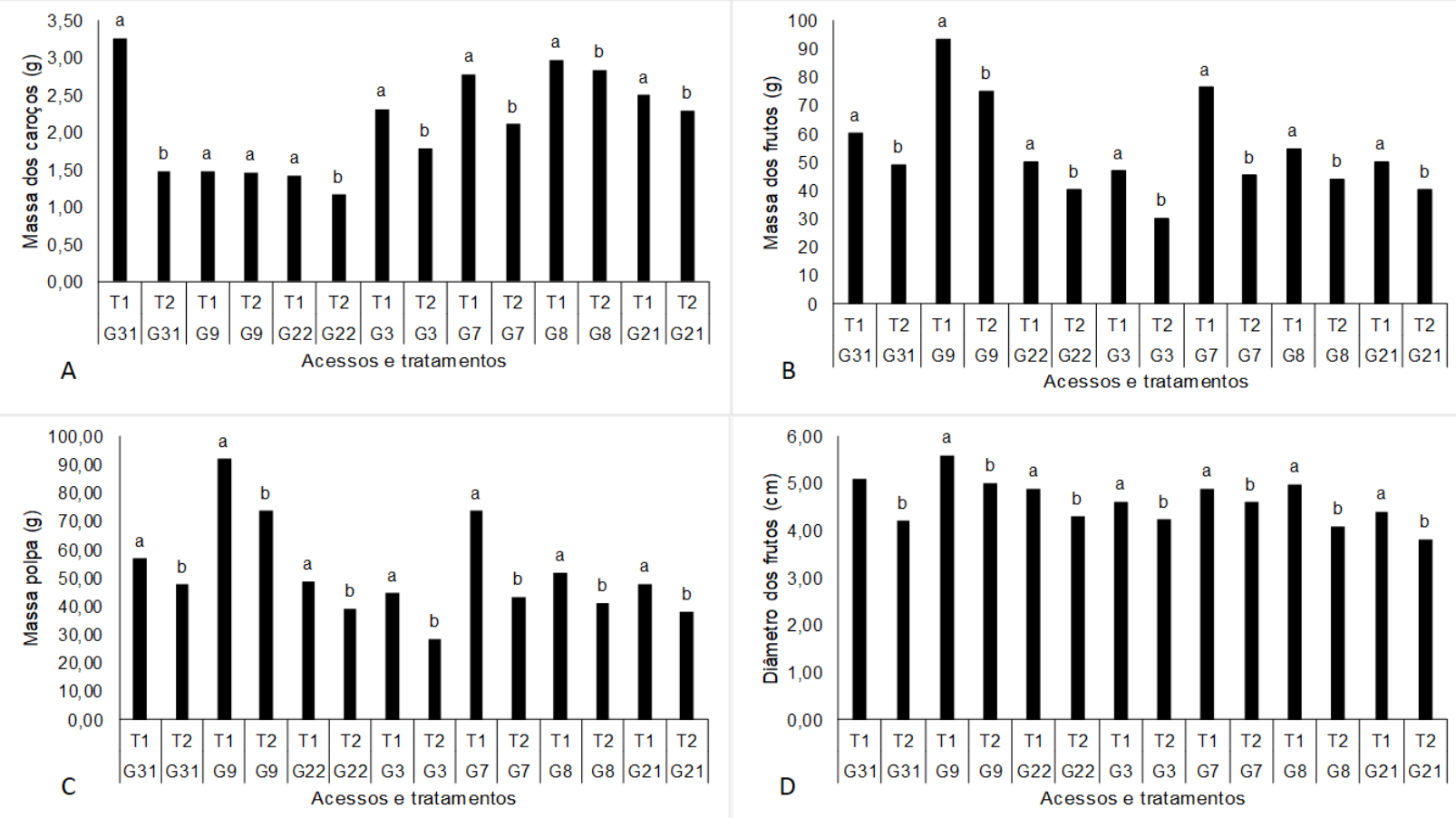

Letras diferentes no mesmo genótipo apresentam variação estatística quando comparados pelo teste de Tukey a 5\%.

OS frutos dos acessos $\mathrm{G} 31$ quando submetidos ao raleio manual apresentam um aumento de tamanho considerável quando se compara com os frutos deste mesmo genótipo quando não são submetidos ao trato cultural. Este aumento no tamanho dos frutos ocorre com valores aproximados de $0,9 \mathrm{~cm}$ fazendo com que os frutos quando submetidos ao raleio sejam classificados de acordo com os parâmetros da tabela 2, como calibre 4.

Frutos do genótipo G9 quando submetidos ao trato cultural do raleio em seus frutos apresentam um aumento de $0,6 \mathrm{~cm}$ quando comparados aos frutos do mesmo genótipo quando não submetidos a este trato cultural. Os fruto dos quando recebem o raleio manual são classificados como calibre 5 enquanto que nos frutos nos quais o raleio não e realizado os fruto são classificados como calibre 4 devido ao tamanho.

Frutos dos acessos G7 são classificados como calibre 4 quando o raleio e realizado ou não nos frutos, enquanto que frutos dos acessos $\mathrm{G} 3 \mathrm{e}$ G8 que receberam a realização do raleio manual são classificados como calibre 4, devido ao aumento do diâmetro dos frutos proporcionado pela realização do trato cultural.
Frutos dos acessos G3 e G8 quando não são raleados apresentam diâmetros inferiores causando uma classificação dos frutos como calibre 3 assim com ocorre nos frutos do acesse G21 classificado nesta categoria mesmo quando raleado.

Quando observamos os dados obtidos por Tutida (2006) quando analisou a incidência de doenças na ameixa através da adubação nitrogenada, apresenta valores de calibre nos frutos da ameixa Reubennel produzidas no Estado do Paraná com valores de calibre Classificados pelo autor com sendo calibre III.

A quantidade de frutos desenvolvidos e classificados em calibre IV no experimento de Dolinski et al. (2007), quando trabalho com adubação em ameixa a quantidade de frutos classificados neste calibre de maior valor comercial diminuem conforme se aumenta o número de frutos colhidos.

Nos frutos da cultivar de ameixa Irati, quando submetidos a diferentes doses de ethephon realizados no trabalho de Pavanello e Ayub (2012) a quantidade de frutos produzidos e classificados como calibre IV diminuiu linearmente com o aumento das doses do produto. 
Tabela 2. Classificação de ameixa utilizada pela EMATER-PR. pessoal.

\begin{tabular}{l|c}
\hline CALIBRE & DIÂMETRO EQUATORIAL $(\mathrm{mm})$ \\
\hline 1 & $>-25<35$ \\
2 & $>=35<40$ \\
3 & $>=40<45$ \\
4 & $>=45<51$ \\
5 & $>=51<57$ \\
6 & $>=57<63$ \\
7 & $>=63<70$ \\
8 & $>=70<80$ \\
9 & $>80$ \\
\hline
\end{tabular}

Fonte: (EMATER-2001)

Quando analisamos a tabela 4 podemos notar que 0 a realização do trato cultural do raleio manual não apresenta influência significativa nos valores relacionados as características químicas dos frutos de ameixa, quando estes valores são submetidos ao teste de Tukey a $5 \%$.

Os frutos de 4 acessos apresentaram uma quantidade de açucares na casa dos $12^{\circ}$ Brix. Este valor quando comparados com a literatura pode ser considerado um valor médio, devido a relatos de frutos de ameixa apresentam grande níveis de variação relacionados ao teor de açúcar nos frutos (SINGH; KHAN, 2010).

Segundo Louw e Theron (2010) quando realizaram estudos com diferentes cultivares de ameixa, eles obtiveram valores relacionados a característica de SST variando de $10.10^{\circ}$ Brix nos frutos da cultivar Pionner até $14.01^{\circ}$ Brix obtidos nos frutos da cultivar Angeleno.

O valor obtido para a característica de SST nos frutos da variedade Horvin, durante trabalhos realizados em 2008, apresentam variação entre 4,01 até 11,76 esta variação ocorre principalmente devido aos diferentes estágios de maturação aos quais as ameixas estavam apresentando no momento da avaliação (PARRA-CORONADO et al., 2008). Frutos obtidos na cultivar de ameixa Black Splendor apresentam uma quantidade de SST de $15.7^{\circ}$ Brix quando estas estão no momento de consumo ideal (BANERJEE et al., 2016).

A variação ocorrida nos SST dos acessos estudados ocorre principalmente pela diferença existente entre a origem dos cruzamentos que originaram frutos de ameixa das cultivares Stanley, Vânat de italia e Tuleu Gras possuem variação entre $6,40^{\circ}$ Brix na variedade Stanley no momento inicial da colheita podendo alcançar valores de até $21.30^{\circ}$ Brix nesta mesma cultivar ou valores de 23,35 e $23,95^{\circ}$ Brix, para as variedades Vanat de Italia e Tuleu Gras respectivamente (VLAIC et al., 2014). Na cultivar Irati os valores de SST obtidos de 9,53 ${ }^{\circ}$ Brix (PAVANELLO, 2012).

Nas cultivares Blackamber e Black splendor valores de ATT nos frutos são de $0.66 \%$ $1,38 \%$ respectivamente está variação está relacionada com o ponto de colheita e o grau de maturação dos frutos, (MINAS et al., 2013). Frutos da cultivar laetitia colhidos possuem acidez entre 1.2 a $1.6 \%$ os valores de acidez apresentam redução quando os frutos são armazenados (ARGENTA et al., 2011).

Frutos de caroços processados devem possuir um grau de maturação elevado em pêssegos da cultivar Aurora 1 durante o processamento mínimo possui valores de ATT por volta de $0,33 \%$ enquanto que com o passar do tempo os frutos apresentam uma quantidade de ATT com 0,27\% (MARTINS et al., 2013).

Em frutos da cultivar Reubennel submetidos a diferentes extratos para o controle de podridões o ratio teve variação entre 15 a $30^{\circ}$ de ratio nos frutos (OLIARI, 2014). Frutos obtidos no acesso 1804 do banco de germoplasma do IAPAR, submetidos a diferentes épocas de realização do raleio manual possuem valores de ratio com variação entre 5,89 até 10,62 , estes valores foram obtidos nos frutos no momento de colheita no qual ainda não tinha apresentado a completa maturação dos frutos (BAUCHROWITZ et al., 2016).

Em frutos da ameixa Gulfblaze quando são submetidos a diferentes épocas de armazenamento em atmosfera modificada apresentam valores variando entre 10,26 até 24,81 (COSTA, 2011). Ameixas de a cultivar Gulfruby quando seus frutos se apresentam com $50 \%$ da sua coloração de casca predominante apresentam valores de ratio de 4,53 (FIORAVANÇO et al., 2008). 
Gráfico 3. Dados químicos obtidos em diferentes acessos de ameixeira japonesa produzidos em Ponta Grossa-PR. Solidos Soluveis Totais (E), Acidez Total Titulável (F) e ratio (G).
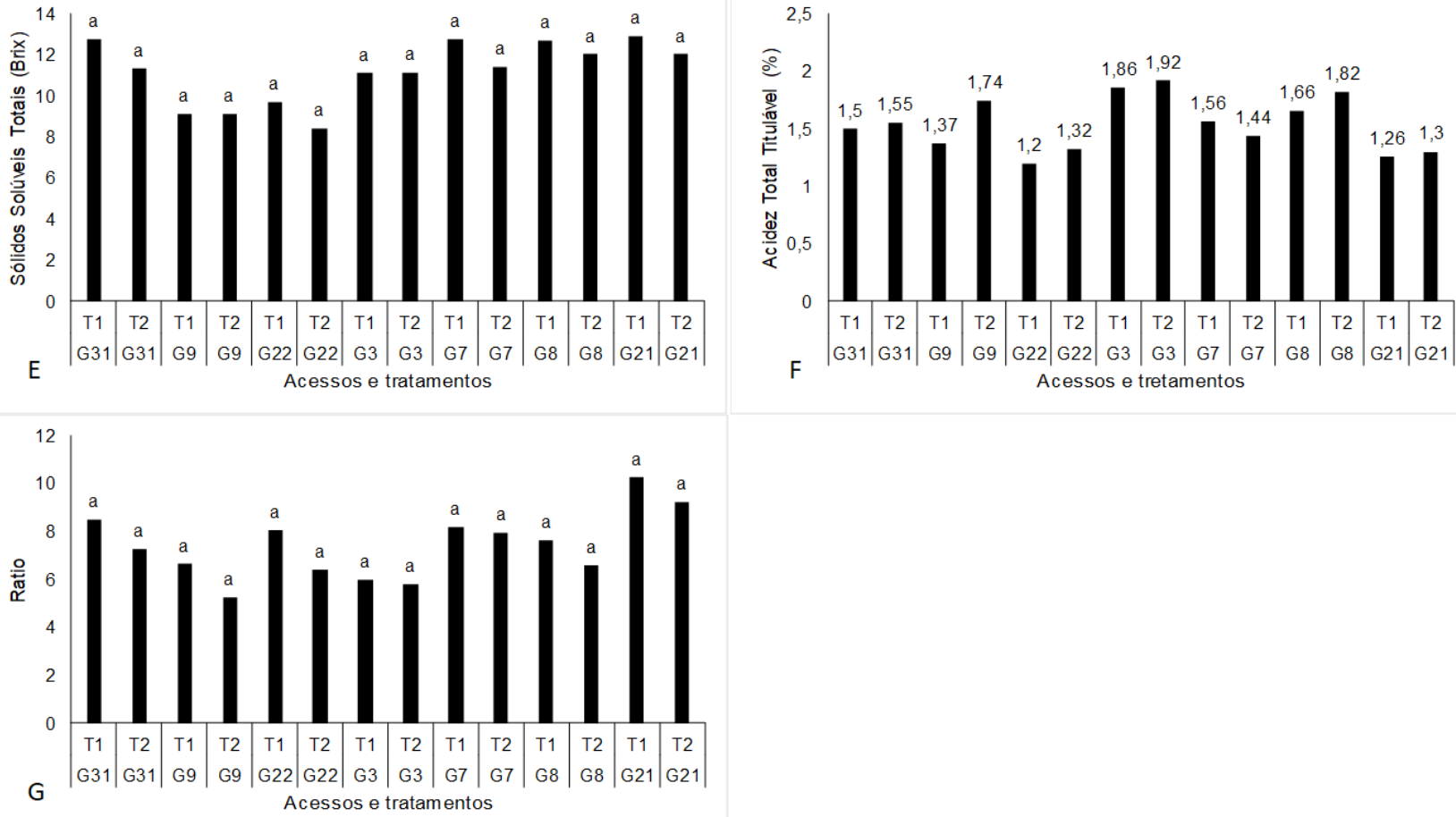

Letras diferentes entre os mesmos acessos apresentam variação estatística quando os dados são submetidos ao teste de Tukey $5 \%$.

\section{CONSIDERAÇÕES FINAIS}

Os acessos utilizados neste experimento apresentaram-se adaptados as condições climáticas do município de Ponta Grossa-PR, amostrando capacidade de produção de frutos neste município.

O raleio manual nos frutos apresentou influência nas qualidades físicas dos frutos, gerando um acréscimo no diâmetro dos frutos, massa dos frutos, massa da polpa e na massa do caroço de forma positiva.

A realização do raleio nos frutos não afeta as qualidades químicas dos frutos.

\section{REFERÊNCIAS}

ARGENTA, L. C.; AMARANTE, C. V. T.; SHIRAYAMA, D.; SCOLARO, A. M. T.; AYUB, R. A. Controle do escurecimento interno de ameixas durante o armazenamento pelo manejo do ponto de colheita e do etileno. Revista Brasileira de Fruticultura, Jaboticabal-sp, v. 33, n. 2, p.376-385, jul. 2011. https://doi.org/10.1590/S0100$\underline{29452011005000051}$

BARBOSA, W.; DALL'ORTO,F.A.C.; OJIMA, M.; MARTINS, F.P.; SANTOS, R.R.; SABINO, J. C. Polinização das fruteiras de caroço: Ameixeira,
Nectarina e Pessegueiro. O Agronômico, Campinas, v.43, n.1, p.108-111, 2001.

BANERJEE, N. et al. Plum polyphenols inhibit colorectal aberrant crypt foci formation in rats: Potential role of the miR-143/AKT/mTOR axis. Nutrition Research, [s.I.], p.1-33, jun. 2016. http://dx.doi.org/10.1016/i.nutres.2016.06.008.

BAUCHROWITZ, I. M.; SILVA, C. M.; KITZBERGER, C. S. G.; EILERT, J. B.; NETO, J. S.; FRANCISCO, A. L. $O$. Avaliação sobre o efeito de diferentes épocas de raleio manual em ameixa japonesa (Prunus salicina lind). Scientia Rural, Ponta Grossa-pr, v. 14, n. 1, p.52-64, dez. 2016.

BAUCHROWITZ, I. M.; SILVA, C. M.; FRANCISCO, A. L. O.; NETO, J. S.; MAÇANEIRO, T. P. Definição das características físico-químicas de três genótipos de ameixa. Scientia Rural, Ponta Grossa-PR, v.15 n.1 p.78-90, Jul. 2017.

BAUCHROWITZ, I. M.; SILVA, C. M.; FRANCISCO, A. L. O.; MAÇANEIRO, T. P. Influência das épocas de raleio manual nas qualidades físicos-quimicas de frutos de ameixa. Scientia Rural, Ponta GrossaPR, v.16 n.1 p.27-38, dez . 2017. 
CASTRO, L. A. S. Botânica. In: CASTRO, L. A. S. (Ed). Ameixa: produção. Pelotas: Embrapa Clima Temperado; Brasília, DF: Embrapa Informação Tecnológica, 2003. p. 34-45. (Frutas do Brasil, 43).

CHAGAS, P. C. Cultivares de ameixas de baixa exigência em frio para regiões subtropicais do estado de São Paulo. 2008. 123 f. Dissertação (Mestrado) - Universidade de São Paulo Escola Superior de Agricultura "Luiz de Queiroz", Piracicaba-SP, 2008.

COSTA, S. M. Condicionamento térmico e irradiação de ameixas 'Gulfblaze' frigorificadas. 2011. 83 f. Tese (Doutorado) - Universidade Estadual Paulista "Júlio de Mesquita Filho", 2011.

DOLINSKI, M. A.; MOTTA, A. C. V.; SERRAT, B. M.; MAY DE MIO, L. L.; MONTEIRO, L. B. Adubação nitrogenada e potássica na produtividade da ameixeira 'Reubennel', na região de Araucária PR. Revista Brasileira de Fruticultura Jaboticabal, v. 29, n. 2, p.364-370, ago. 2007.

DUCROQUET, J.P.H.J.; DALBÓ, M. A. SCS 409 Camila e SCS 410 Piuna - novas cultivares de ameixeira com resistência á escaldadura das Folhas. Revista Agropecuária Catarinense, V.20, n.1, mar. 2007. P. 67-70.

EPAGRI. Frutas de clima temperado. Disponível em: $\quad$ http://www.epagri.sc.gov.br/wpcontent/uploads/2013/10/FRUTICULTURA 2009 2010.pdf.

FACHINELLO, J. C. et al. Situação e Perspectivas da Fruticultura de Clima Temperado no Brasil. Revista Brasileira de Fruticultura, p. 109-120, $2011 . \quad$ https://doi.org/10.1590/S010029452011000500014

FACHINELLO, J.C.; NACHTIGAL, J.C.; KERSTEN, E. Poda das plantas frutíferas. In: FACHINELLO, J.C.; NACHTIGAL, J.C.; KERSTEN, E. Fruticultura: fundamentos e práticas. Pelotas: Embrapa Clima Temperado, 2008. p.93-102

FERREIRA, D. F. Sisvar: a Guide for its Bootstrap procedures in multiple comparisons. Ciênc. agrotec. [online], v.38, n.2, p.109-112, 2014. https://doi.org/10.1590/S1413$\underline{70542014000200001}$
FIORAVANÇO, J. C.; SIMONETTO, P. R.; GRELLMANN, E. O. 'Gulfruby': Cultivar precoce de ameixeira japonesa com potencial para cultivo na região serrana do RS. Pesq. Agrop. Gaúcha, Porto Alegre, v. 14, n. 2, p.81-85, jul. 2008.

FONSECA, N.; SILVA, S.O.; SAMPAIO, J.M. Caracterização e avaliação de cultivares de manga na região do recôncavo baiano. Revista Brasileira de Fruticultura, Cruz das Almas, v.16, n.3, p.29-45, dez. 1994.

IAPAR. Cartas Climáticas do Paraná. Versão 1.0. 2000

LOUW, E. D.; THERON, K. I. Robust prediction models for quality parameters in Japanese plums (Prunus salicina L.) using NIR spectroscopy. Postharvest Biology And Technology, [s.I.], v. 58, n. 3, p.176-184, dez. 2010.

https://doi.org/10.1016/j.postharvbio.2010.07.00 $\underline{1}$

MARTINS, R. N.; MATTIUZ, B.; SANTOS, L. O.; HOJO, E. T. D.; MATTUZ, C. F. M. Estádios de maturação de pêssegos 'Aurora-1' para o processamento mínimo. Revista Brasileira de Fruticultura, Jaboticabal-sp, v. 35, n. 2, p.391-397, jul. 2013. https://doi.org/10.1590/S0100$\underline{29452013000200008}$

MINAS, I. S.; CRISOSTO, G. M.; HOLCROFT, D.; VASILAKAKIS, M.; CRISOSTO, C. H. Postharvest handling of plums (Prunus salicina Lindl.) at $10^{\circ} \mathrm{C}$ to save energy and preserve fruit quality using an innovative application system of 1MCP. Postharvest Biology And Technology, [s.I.], v. 76, p.1-9, fev. 2013. https://doi.org/10.1016/j.postharvbio.2012.08.01 $\underline{3}$

OLIARI, I. C. R. Extrato de algas no controle da podridão parda e na qualidade pós-colheita de ameixas. 2014. 90 f. Dissertação (Mestrado) Universidade Estadual do Centro-Oeste, Guarapuava-PR, 2014.

OLIVEIRA, R. S.; RAMOS, J. D.; OLIVEIRA, M. C.; CRUZ, M. C. Crescimento vegetativo e fenologia de ameixeira sob cultivo orgânico na Região de Delfim Moreira - MG. Revista Agrarian, Dourados, v. 5, n. 17, p.198-205, dez. 2012. 
OLIVEIRA, J.; SILVA, P. P. M.; SPOTO, M. H. F. Atmosfera modificada e refrigeração para conservação pós-colheita de Camu-camu. Ciência Rural, Santa Maria, v. 44, n.6, p. 1126-1133, 2014. https://doi.org/10.1590/S0103-

84782014000600028

PAIVA, M.C.; MANICA, I. FIORAVANÇO, J.C. Competição entre quatro cultivares e três seleções de goiabas em Eldorado do Sul, RS. Pesquisa Agropecuária Brasileira, Brasília, v.29, n.26, p.917-922, jun. 1994.

PARRA-CORONADO, A.; HERNÁNDEZ, J. E. H.; CAMACHO-TAMAYO, J. H. Estudio fisiológico poscosecha y evaluación de la calidad de la ciruela variedad Horvin (prunus domestica l.) bajo tres condiciones de almacenamiento refrigerado: Post-harvest physiological study and evaluation of the quality of Cultivar Horvin plums (prunus domestica I.) in three cold-storage conditions. Revista Ingeniería e Investigación, S.I, v. 1, n. 28, p.99-104, abr. 2008.

PAVANELLO, A. P.; AYUB, R. A. Aplicação de ethephon no raleio químico de ameixeira e seu Efeito Sobre a Produtividade. Revista Brasileira de Fruticultura, Jaboticabal, v.34, n.1, p.309-316, 2012.

PAVANELLO, A. P.; AYUB, R. A. Raleio químico de frutos de ameixeira com ethephon. Ciência Rural, [s.l.], v. 44, n. 10, p.1766-1769, out. 2014. https://doi.org/10.1590/0103-8478cr20131097

SEAB. Fruticultura. Disponível em: http://www.agricultura.pr.gov.br/arquivos/File/d eral/Prognosticos/fruticultura 201213.
Secretaria de Estado da Agricultura e do Abastecimento (SEAB). Fruticultura. Disponível em:

http://www.agricultura.pr.gov.br/arquivos/File/d eral/Prognosticos/fruticultura 2014 15.pdf.

SINGH, Z.; KHAN, A. S. Physiology of plum fruit ripening. Stewart Postharvest Review, [s.I.], v. 6, n. 2, p.1-10, 1 jun. 2010. https://doi.org/10.2212/spr.2010.2.3

TUTIDA, I. Influência do nitrogênio e do potássio na intensidade de doenças fúngicas e na qualidade dos frutos em ameixeira. 2006. $110 \mathrm{f}$. Dissertação (Mestrado) - Universidade Federal do Paraná, Curitiba-PR, 2006.

VLAIC, R. A. et al. Physico-Chemical Changes during Growth and Development of Three Plum Varieties. Bulletin Of University Of Agricultural Sciences And Veterinary Medicine Cluj-napoca. Food Science And Technology, [s.I.], v. 71, n. 2, p.131-135, 24 nov. 2014. https://doi.org/10.15835/buasvmcn-fst:10686

Recebido para publicação em 26/09/2017

Revisado em 03/02/2018

Aceito em 26/03/2018 